\title{
HCV Genetic Elements Determining the Early Response to Peginterferon and Ribavirin Therapy
}

\author{
Nobuyuki Enomoto Shinya Maekawa \\ First Department of Medicine, Faculty of Medicine, University of Yamanashi, Chuo, Japan
}

\section{Key Words}

Full open reading frame analysis $\cdot$ Hepatitis $C$ virus .

Peginterferon/ribavirin therapy

\begin{abstract}
The aim of this study was to search hepatitis C virus (HCV) genetic elements determining the early response to peginterferon/ribavirin therapy using HCV genome-wide analysis. From a total of 88 chronic hepatitis $C$ patients with HCV-1b treated with peginterferon/ribavirin, the whole HCV amino acid sequence was determined and analyzed according to the viral response during the treatment. Mutations in NS5AISDR (interferon sensitivity-determining region) are associated with rapid viral response at week 4 , and the core arginine70glutamine (R70Q) mutation is associated with no early viral response at week 12 , revealing that core 70 and NS5A are the most important factors determining the virological kinetics during peginterferon and ribavirin therapy.
\end{abstract}

Copyright $\odot 2010$ S. Karger AG, Basel

\section{Introduction}

Hepatitis $\mathrm{C}$ virus (HCV) is a major cause of chronic liver diseases, and worldwide 170 million people are infected with HCV. With the introduction of the recent combination therapy of pegylated-interferon (PEG-IFN) and ribavirin (RBV), half of patients can eradicate the virus (sustained virological response, SVR). The SVR rate of HCV to the PEG-IFN/RBV therapy is dependent on $\mathrm{HCV}$ genotypes, and the viral kinetics during the treatment strongly affect the final viral clearance $[1,2]$. It is generally considered that HCV structures affect the treatment response since the SVR rate to PEG-IFN/RBV therapy depends upon viral genotypes as described above. However, comprehensive analysis of the contribution of HCV structures to different responses has not yet been conducted. In the present study, in order to clarify the relationship between HCV sequences and viral responses, we have determined the complete $\mathrm{HCV}$ open reading frame sequences obtained from pretreatment patients' serum, and investigated their response by searching for $\mathrm{HCV}$ genetic elements determining the early response to PEG-IFN/RBV therapy using HCV genome-wide analysis.

\section{Methods}

A total of 88 chronic hepatitis $\mathrm{C}$ patients with $\mathrm{HCV}-1 \mathrm{~b}$ treated with PEG-IFN/RBV were studied. From pretreatment sera, the whole HCV deduced amino acid sequence (3,010 amino acids) was determined in each patient by direct RT-PCR.

\section{KARGER}

Fax +41613061234 E-Mail karger@karger.ch www.karger.com
(C) 2010 S. Karger AG, Basel

0300-5526/10/0531-0066 \$26.00/0

Accessible online at:

www.karger.com/int
Nobuyuki Enomoto, MD

First Department of Medicine, Faculty of Medicine

University of Yamanashi

1110 Shimokato, Chuo, Yamanashi 409-3898 (Japan)

Tel. +81 55273 9584, Fax +81 55273 6748, E-Mail enomoto@ yamanashi.ac.jp 


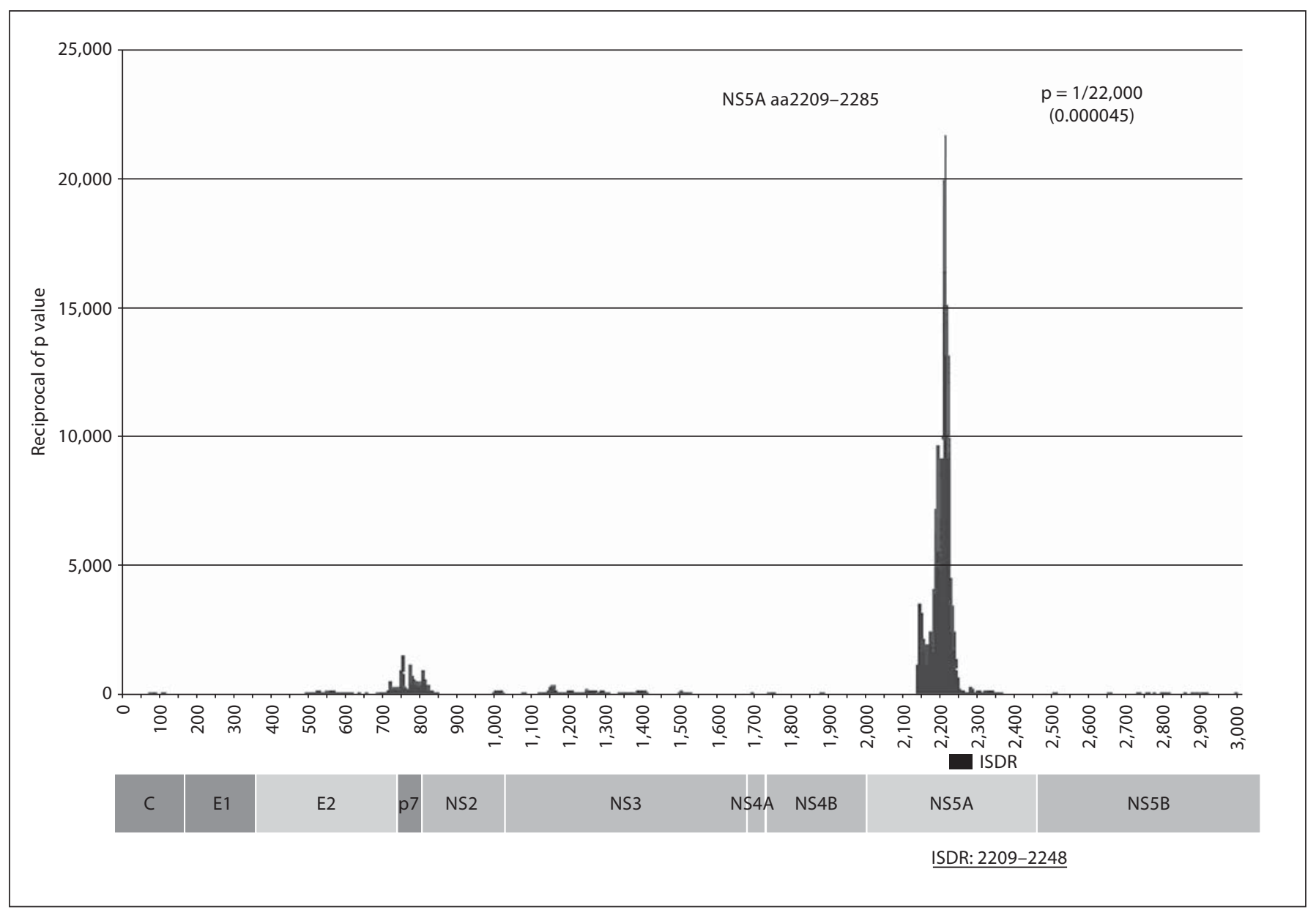

Fig. 1. Reciprocal of $\mathrm{p}$ value for sliding window analysis with 77 amino acid width for RVR versus others.

Amino acid usage of each of the 3,010 positions was compared according to the different virological response in order to identify the single amino acid differences determining the virological response. In addition, sliding window analyses were carried out in order to identify the amino acid region associated with the virological response. The number of the amino acid changes in the fixed stretch of the sequence (window: 2-100 amino acids) were compared according to the virological response, scanning the whole $\mathrm{HCV}$ amino acid sequence by sliding this window one by one.

\section{Results}

Of 88 patients studied, 9 showed rapid viral response (RVR; HCV-RNA undetectable at week 4) and 71 showed early viral response (EVR; over 2-log drop of HCV-RNA at week 12). The other 17 patients showed no EVR, indicating these patients are highly resistant to the treatment.

HCV Genetic Elements and Early Response to PEG-IFN/RBV
Mutations in the region overlapping NS5A-ISDR (interferon sensitivity-determining region, aa2209-2248) are associated with the good response to PEG-IFN/RBV therapy as shown in sliding window analysis comparing RVR patients at week 4 and others (fig. 1). In contrast, the core $\mathrm{R}$ (arginine)70Q (glutamine) mutation is associated with a poor response resulting in no EVR at week 12 by single amino difference analysis comparing non-EVR patients and the others (fig. 2).

\section{Discussion}

In the present study, using a sliding window analysis comparing all $\mathrm{HCV}$ amino acids, the amino acid region located in ISDR was extracted as the most significant region discriminating the RVR and non-RVR patients. By

Intervirology 2010;53:66-69 


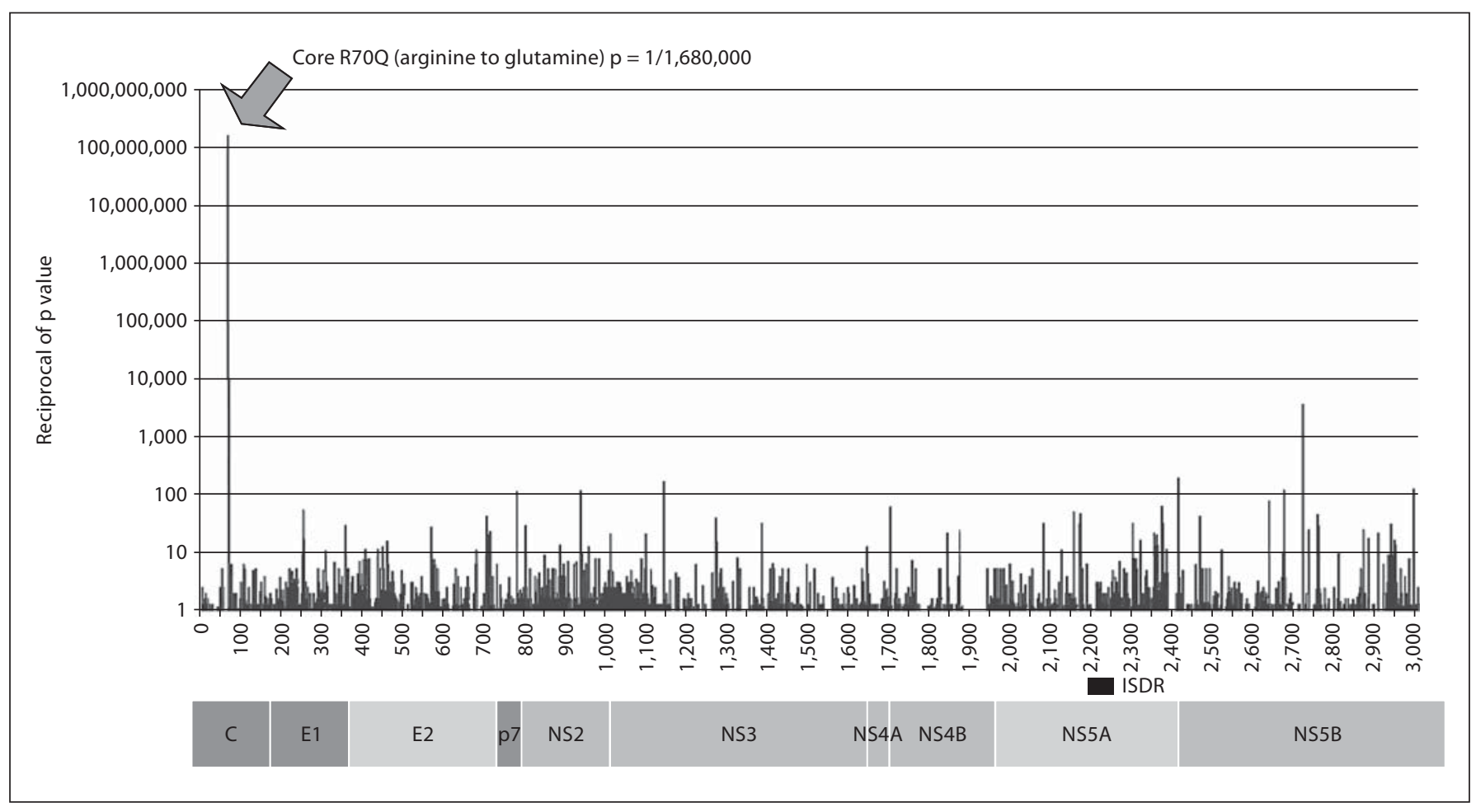

Fig. 2. Reciprocal of $\mathrm{p}$ value for single amino acid difference along the whole HCV sequence for non-EVR versus others.

comparing amino acids between the non-EVR patients and the others, remarkable differences were clustered in a single amino acid polymorphism in the core 70 . Recent studies have proven that the initial viral response at week 4 and week 12 of the PEG-IFN/RBV therapy could be a useful predictor of the final outcome, indicating that the present findings are important for predicting treatment outcome and individualizing the treatment regimen for each patient as well as understanding the mechanism of diverse response to PEG-IFN/RBV therapy.

ISDR was first identified as the region significantly related to SVR in the era of IFN monotherapy in Japanese patients $[3,4]$. 'Mutant type', meaning 4 or more mutations in the region, was associated with high SVR rate, while the rate was low in the 'intermediate type' (1-3 mutations) and wild type (no mutation). Though there were controversies as to the predictive value of ISDR, since studies in Europe and in North America did not necessarily reproduce evident correlation between ISDR and SVR, a recent meta-analysis proved its value by demonstrating a clear relationship all over the world, even in Western countries [5]. The present study reproduced the significance of ISDR in PEG-IFN/RBV therapy. Muta- tions in ISDR make HCV highly sensitive to IFN, leading to RVR. Current guidelines indicate that RVR patients with low viral load before treatment can be treated with 24 weeks instead of the standard 48 weeks of therapy. Since most ISDR mutant patients show low viral loads, these easy-to-treat patients in genotype $1 \mathrm{~b}$ should be mainly infected with HCV with ISDR mutations, suggesting ISDR genotyping would identify the patients treatable with the abbreviated regimen.

On the other hand, in the present study, the polymorphism of core 70 was extracted as the most significant position to determine poor virological response in 12 weeks (non-EVR). The contribution of core region amino acid polymorphism in resistance to (PEG-)IFN/RBV therapy was previously reported by Akuta et al. [6], who first found that the polymorphisms in a combination of core 70 and 91 were closely related to the final outcome. The importance of core 70 polymorphism alone, however, was considered rather weak in their study for its smaller $\mathrm{p}$ value. Their end point was the final outcome of the treatment, which could be influenced by a variety of factors other than viral genetics, such as host factors (age, sex, fibrosis, body weight, etc.) and treatment (dose of 
PEG-IFN/RBV). Further studies are needed to clarify the significance of the core mutations for final outcome of the treatment in the context of the HCV genome-wide analysis.

Different viral responses by polymorphisms in core 70 were also recently suggested in North American patients by Donlin et al. [7]. However, it was reported that the association with core 70 was weaker in their study. Very recently, the IL28B (interferon-lambda-3) gene polymorphism has been found to be closely associated with treatment response in patients in the United States, European Union and Japan by human genome-wide analysis [8-10]. The favorable IL28B genotype is found most frequently in Asian patients, second in European-Americans, and least in African-Americans, indicating that a well-known racial difference in treatment efficacy can be explained by the IL28B polymorphism. The interaction between viral and human genome polymorphisms should be studied further with regard to the treatment response.

\section{Conclusion}

HCV genome-wide analysis with a large number of patients successfully revealed that core 70 and NS5A are the most important factors determining the virological kinetics during PEG-IFN/RBV therapy. Viral genomewide analysis is a promising tool for elucidating the unknown viral factors for different pathological pictures, such as disease progression.

\section{Disclosure Statement}

Supported in part by a Grant-in-Aid for Research on Hepatitis (grant ID H19-002) from the Ministry of Health, Labor, and Welfare, Japan. The authors report receiving grant support from Schering-Plough and Roche.

\section{References}

1 Neumann AU, Pianko S, Zeuzem S, Yoshida EM, Benhamou Y, Mishan M, et al: Positive and negative prediction of sustained virologic response at weeks 2 and 4 of treatment with albinterferon alfa-2b or peginterferon alfa-2a in treatment-naive patients with genotype 1, chronic hepatitis C. J Hepatol 2009; 51:21-28.

-2 Lee SS, Ferenci P: Optimizing outcomes in patients with hepatitis $C$ virus genotype 1 or 4. Antivir Ther 2008;13(suppl 1):9-16.

-3 Enomoto N, Sakuma I, Asahina Y, Kurosaki M, Murakami T, Yamamoto C, et al: Comparison of full-length sequences of interferon-sensitive and resistant hepatitis $C$ virus $1 \mathrm{~b}$ : sensitivity to interferon is conferred by amino acid substitutions in the NS5A region. J Clin Invest 1995;96:224-230.
-4 Enomoto N, Sakuma I, Asahina Y, Kurosaki M, Murakami T, Yamamoto C, et al: Mutations in the nonstructural protein $5 \mathrm{~A}$ gene and response to interferon in patients with chronic hepatitis $\mathrm{C}$ virus $1 \mathrm{~b}$ infection. $\mathrm{N}$ Engl J Med 1996;334:77-81.

-5 Pascu M, Martus P, Hohne M, Wiedenmann B, Hopf U, Schreier E, et al: Sustained virological response in hepatitis $\mathrm{C}$ virus type $1 \mathrm{~b}$ infected patients is predicted by the number of mutations within the NS5A-ISDR: a metaanalysis focused on geographical differences. Gut 2004;53:1345-1351.

6 Akuta N, Suzuki F, Sezaki H, Suzuki Y, Hosaka T, Someya T, et al: Association of amino acid substitution pattern in core protein of hepatitis $\mathrm{C}$ virus genotype $1 \mathrm{~b}$ high viral load and non-virological response to interferonribavirin combination therapy. Intervirology $2005 ; 48: 372-380$.
7 Donlin MJ, Cannon NA, Yao E, Li J, Wahed A, Taylor MW, et al: Pretreatment sequence diversity differences in the full-length hepatitis $\mathrm{C}$ virus open reading frame correlate with early response to therapy. J Virol 2007; 81:8211-8224.

8 Ge D, Fellay J, Thompson AJ, Simon JS, Shianna KV, Urban TJ, et al: Genetic variation in IL28B predicts hepatitis C treatment-induced viral clearance. Nature 2009;461:399401.

-9 Suppiah V, Moldovan M, Ahlenstiel G: IL28B is associated with response to chronic hepatitis $C$ interferon- $\alpha$ and ribavirin therapy. Nat Genet 2009;41:1100-1104.

10 Tanaka Y, Nishida N, Sugiyama M, Kurosaki M, Matsuura K, Sakamoto N, et al: Genomewide association of $I L 28 B$ with response to pegylated interferon- $\alpha$ and ribavirin therapy for chronic hepatitis C. Nat Genet 2009; 41:1105-1109. 